\title{
АНАЛИЗ И ОЦЕНКА ВЛИЯНИЯ СОСТОЯНИЯ РЕГИОНА НА ЕГО ИНВЕСТИЦИОННУЮ ПРИВЛЕКАТЕЛЬНОСТЬ НА ОСНОВЕ СРАВНЕНИЯ РАЗЛИЧНЫХ МЕТОДИК (НА ПРИМЕРЕ РЕГИОНОВ АРКТИЧЕСКОЙ ЗОНЫ РФ)
}

\author{
(c) 2020 Никифорова Елена Владимировна \\ доктор экономических наук, профессор, профессор Департамента бизнес-анализа \\ Финансовый университет при Правительстве РФ, Россия, Москва \\ E-mail:EVNikiforova@fa.ru
}

\section{(c) 2020 Гизатуллина Ольга Михайловна}

кандидат экономических наук, доцент, доцент Департамента учета, анализа и аудита Финансовый университет при Правительстве РФ, Россия, Москва

E-mail: OMGizatullina@fa.ru

\section{(c) 2020 Ушанов Игорь Геннадьевич}

кандидат экономических наук, старший преподаватель Департамента учета, анализа и аудита Финансовый университет при Правительстве РФ, Россия, Москва

E-mail: IGUshanov@fa.ru

\section{(c) 2020 Шнайдер Ольга Владимировна}

кандидат экономических наук, доцент, доцент Департамента учета, анализа и аудита Финансовый университет при Правительстве РФ, Россия, Москва

\section{E-mail: OVSHnajder@fa.ru}

Инвестиционная привлекательность регионов Российской Федерации в настоящее время является приоритетным аналитическим направлением для ведущих специалистов в области экономического развития страны. На сегодняшний день инвестиционная привлекательность выступает в роли обязательного условия конкурентоспособности субъектов Российской Федерации. В статье исследуется состояние арктического региона Российской Федерации и ключевые факторы, оказывающие влияние на уровень его инвестиционной привлекательности.

Арктическая зона Российской Федерации является потенциальной точкой роста отечественной экономики и приоритетным направлением инвестирования. Практика анализа и оценки инвестиционной привлекательности регионального уровня базируется на наиболее распространенном подходе, основанном на формировании интегрального показателя. Оценка инвестиционной привлекательности формируется на основе статистической обработки и анализа большого числа показателей, характеризующих различные параметры осуществления предпринимательской деятельности, в том числе и в регионе.

Основная проблема анализа и оценки инвестиционной привлекательности российских регионов потенциальными инвесторами и прочими стейкхолдерами проявляется через отсутствие методического единства в этом вопросе. В свою очередь состояние региональной экономики и развитие регионов в целом влияют на оценку инвестиционной привлекательности, что и обуславливает необходимость разработки методологических аспектов.

Ключевые слова: анализ, арктическая зона, инвестиционная привлекательность, потенциал, риск, регион, рейтинг, показатели, социальные факторы, устойчивое развитие, экологические факторы.

На сегодняшний день инвестиционная привлекательность выступает в роли обязательного условия конкурентоспособности субъектов Российской Федерации, ключевого фактора формирования их устойчивого развития, в том числе экономики региона. Приток инвестиций в экономику того или иного региона способствует ускорению процессов модернизации производственных предприятий, продвижению инноваций, производству инновационной про-

\footnotetext{
* Статья подготовлена по результатам исследований, выполненных за счет бюджетных средств по государственному заданию Финуниверситету
} 
дукции, оптимизации логистических затрат, а также повышению социальной и экологической эффективности и промышленного потенциала региона, благосостояния и качества жизни населения, а значит обеспечивает, в конечном итоге, устойчивое развитие региона. С другой стороны, рост экономики субъектов Российской Федерации, ускорение темпов роста регионального продукта способствуют достижению сбалансированности региональных бюджетов, обеспечивают стабильность налоговых поступлений в федеральный бюджет.

В современных условиях повышение инвестиционной привлекательности отдельных регионов Российской Федерации, способных выступить в качестве точек роста всей российской экономики, к которым относятся регионы арктической зоны нашей страны, является одной из приоритетных задач, решение которых осуществляется на высшем государственном уровне [1].

Инвестиционную привлекательность региона характеризует определенный набор экономико-социальных, управленческоорганизационных, политико-правовых предпосылок, выраженных в форме финансовых и нефинансовых индикаторов, позволяющих оценить степень соответствия условий и результатов осуществления инвестиционной деятельности в регионе ожиданиям потенциальных ин- весторов [1, 2].

Анализ инвестиционной привлекательности территорий в соответствие с подходом Гарвардской школы бизнеса базируется на экспертной оценке основных категорий (рисунок 1) [3].

Обзор отечественной практики позволяет сделать вывод, что наиболее распространенным выступает подход, в основе которого лежит формирование интегрального показателя. Показатель интегрального значения получается на основе статистической обработке и анализе большого числа показателей, характеризующих различные параметры, что в целом дает оценку инвестиционной привлекательности региона.

Однако, существенной проблемой при проведении анализа и оценки инвестиционной привлекательности российских регионов потенциальными инвесторами и прочими заинтересованными сторонами может стать многообразие мнений определяющих подходы при формировании оценки инвестиционной привлекательности региона, а также отсутствие методического единства в этом вопросе, возможность неоднозначной трактовки отдельных критериев. С целью проведения анализа и оценки влияния состояния региона на его инвестиционную привлекательность и определения обоснованных критериев анализа в числе наиболее авторитетных методик выделяют ряд методик (см. рисунок 2).

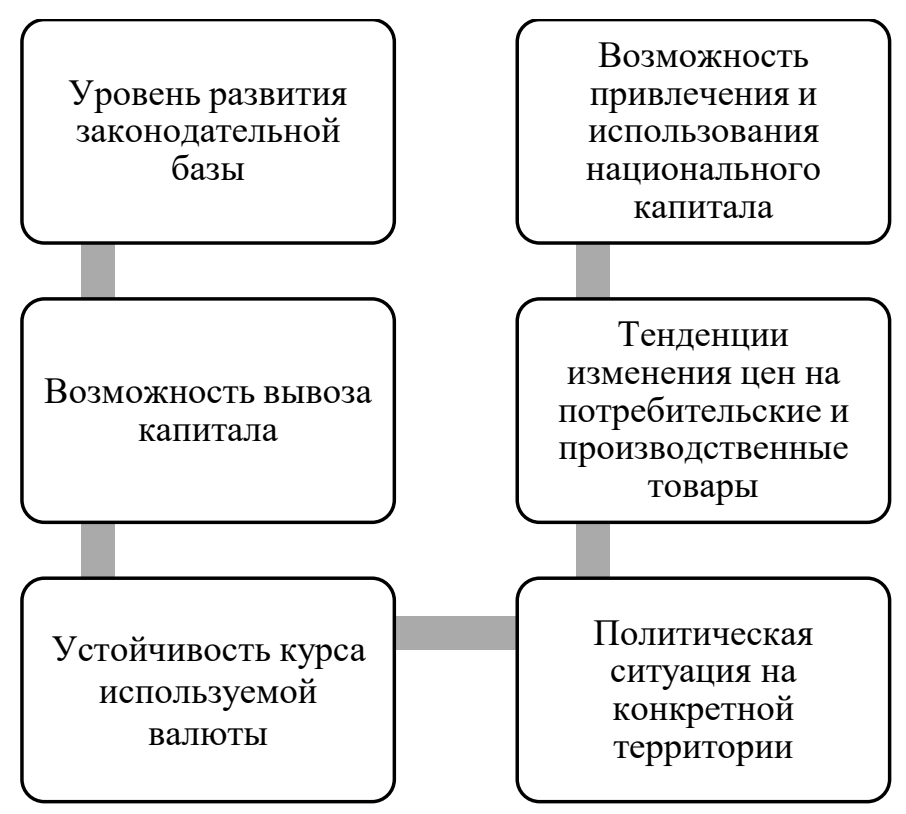

Рисунок 1. Основные критерии экспертной оценки инвестиционной привлекательности территорий по Гарвардской школе бизнеса 
1) методика расчета национального рейтинга состояния инвестиционного климата в субъектах Российской Федерации Агентства стратегических инициатив (АСИ)

2) методика расчета рейтинга инвестиционной привлекательности субъектов Российской Федерации Национального рейтингового агентства (HPA)

3) методика расчета рейтинга инвестиционной привлекательности регионов Российской Федерации рейтингового агентства RAEX (Эксперт PA)

4) методика Института экономики РАН

5) методика Совета по изучению производительных сил Минэкономразвития РФ и РАН

Рисунок 2. Практико-ориентированные методики оценки инвестиционной привлекательности

Приоритет отдается методикам определяющим рейтинг инвестиционной привлекательности. Ключевыми источниками информации при расчете рейтинга выступают статистические данные. Статистические данные предоставляются Росстатом, ЦБ РФ, Министерством финансов и пр. Уникальность метода рейтинга инвестиционной привлекательности еще и в том, что при сборе данных метод учитывает результаты опросов независимых экспертов и аналитиков HPA.

Методика инвестиционной привлекательности, разработанная специалистами Института экономики РАН, подразумевает использование более 70 показателей, большинство из которых предполагает экспертную оценку и лишь незначительное количество показателей носит статистический характер. Для проведения оценки методика предполагает формирование коллектива экспертов из представителей различных профессиональных групп.

Ключевой особенностью методики Минэкономразвития Российской Федерации и РАН является тот факт, что инвестиционный потенци- ал региона анализируется и интерпретируется через призму таких категорий как «инвестиционная привлекательность» и «инвестиционная активность», что дает возможность проследить наличие причинно-следственных связей между предпосылками (наличием привлекательных для потенциальных инвесторов факторных характеристик региона) и результатами (достигнутый уровень реальной инвестиционной деятельности в данном регионе). Подобный подход несет в себе, помимо прочего, потенциал снижения субъективности оценки эффективности усилий органов региональной и федеральной власти по повышению инвестиционной привлекательности конкретных субъектов Российской Федерации.

Так же следует отметить, что еще одним преимуществом выше обозначенной методики является возможность обоснования достоверности результатов путем использования критерия тесноты связи между показателями, участвующими в оценке, а также минимальное использование экспертных оценок [4].

Национальным рейтинговым агентством 
Таблица 1. Рейтинг инвестиционной привлекательности регионов Арктики российской зоны за 2019 г.

\begin{tabular}{|c|c|c|}
\hline Регион / Region & Рейтинг 2019 г. & Изменение 2018-2019 гг. \\
\hline Ямало-Ненецкий АО & IC2 & Подтвержден \\
\hline Ненецкий АО & IC3 & Подтвержден \\
\hline Красноярский край & IC4 & Подтвержден \\
\hline Мурманская область & IC4 & Повышен \\
\hline Республика Саха (Якутия) & IC5 & Понижен \\
\hline Архангельская область & IC5 & Повышен \\
\hline Чукотский АО & IC5 & Понижен \\
\hline Республика Карелия & IC6 & Подтвержден \\
\hline Республика Коми & IC7 & Понижен \\
\hline
\end{tabular}

Источник: VII ежегодный рейтинг инвестиционной привлекательности регионов России 2019. Национальное рейтинговое агентство [5, 6, 7]

Российской Федерации опубликованы результаты рейтинговой инвестиционной привлекательности регионов Арктики российской зоны (см. таблицу 1).

В заключении отметим, что перечисленный выше перечень факторов не является исчерпывающим для выявления уровня инвестиционной привлекательности того или иного региона Российской Федерации, поскольку само понимание инвестором преимуществ и рисков вложения средств в определенный проект зачастую носит субъективный характер, однако количественная оценка данных факторов и анализ их качественных характеристик в системе координат «потенциал-риск» на основе релевантной информации для конкретного региона позволит приблизиться к пониманию его инвестиционной привлекательности с точки зрения рационального поведения инвестора.

\section{Библиографический список}

1. Абрамов Д.В., Быкова А.А. Проблемы инвестиционной привлекательности ведущих российских регионов и регионов европейских стран. Проблемы совершенствования организации производства и управления промышленными предприятиями: межвузовский сборник научных трудов. Самарский государственный экономический университет. Самара, 2017(1):232-236.

2. Лазарева Е.И., Анопченко Т.Ю. Эконометрическая оценка инвестиционной привлекательности как основа формирования кластерной инвестиционной стратегии региона. Вестник Самарского государственного экономического университета. 2016;5(139):21-26.

3. Куриков В.М., Ташланова Ю.В. Методология оценки инвестиционной привлекательности региона. Вестник Алтайской академии экономики и права. 2019;5:99-103.

4. Аникина М.И. Передовые методики оценки инвестиционной привлекательности регионов России. Наука вчера, сегодня, завтра: сб. ст. по матер. XXXVI междунар. науч.-практ. конф. СибАК. Новосибирск. 2016;7(29):144-151.

5. Рейтинг инвестиционной привлекательности субъектов Российской Федерации Национального рейтингового агентства. Методология. URL: http://www.ra-national.ru/ru/rating_field/field_rat_qual_invest_reg_dist Дата обращения: 20.10.2020.

6. Рейтинг инвестиционной привлекательности регионов России - 2019 RAEX: результаты и основные выводы. URL: https://raex-a.ru/files/REG_2019_Analytica_Block_Web.pdf Дата обращения: 17.09.2020.

7. http://elibrary.ru/item.asp?id=42981926. 